\title{
Comparison of Time Adjustment Clauses between DZ3910, AS4000 and STCC
}

David Finnie, (Otago Polytechnic, New Zealand)

\begin{abstract}
This article examines time adjustment clauses, as they relate to time adjustment between standard terms of construction contracts. DZ3910, AS4000 and STCC were compared on the basis of how risks are allocated, how this may impact on the contractor's pricing, and ease of understanding for each clause. ASTCC was found to be the most easily interpreted contract, followed by AS4000 and then NZS3910. These assessments were based on the following: a) whether each contract contains words with multiple meanings, b) the number of words used per sentence, c) the amount of internal cross-referencing, and d) the clarity of the contract structure. The allowable pre-conditions for the contractor to claim a time adjustment are similar for all three contracts, and none of them expressly state which party is to bear the risk of buildability, or address the risk of a designer's disclaimer clause. All of the contracts adopt the principle of contra preferentum which means that the employer bares the risk of variance if there are any ambiguities in the design documentation. Due to their similarities of risk allocation, all of the contracts provide the employer with a similar amount of price surety. AS4000 is the only contract to contain a stringent time-bar clause, limiting a contractor's time adjustment claim. ASTCC requires the contractor to apply 'immediately' and DZ3910 provides a time-bar of 20 working days or as soon as practicable. None of the contracts clarify whether their timing requirements take precedence over the prevention principle, or over any other ground for claiming a time adjustment. The effect of DZ3910's pre-notification clause 5.19 .3 is discussed, and an alternative contents structure is recommended for DZ3910, using a project management method.
\end{abstract}

\section{Introduction}

An important aspect of any construction contract is the legal machinery to deal with time adjustments throughout the course of the project. In standard terms of contract, these provisions are commonly called extensions of time (EOT).

This report will compare and critique three conditions of contract:

1. Australian Standard AS 4000 - 1997 General Conditions of Contract

2. Standard Terms of Contract for Small Projects 2012: This is a contract recently drafted by Naseem Ameer Ali, lecturer at Massey University

3. New Zealand Standard NZ3910: 2003 Conditions of Contract for Building and Civil Engineering Construction which is currently being revised to DZS3910. Opportunity for public comment has recently closed, through Standards New Zealand, for its revision

For the purpose of this report, these standard terms of contract will be abbreviated to, AS4000, ASTCC and DZS3910 respectively. Each of these contract clauses will be compared and critically reviewed in relation to the way that they allocate risks between parties; how this may affect the contractor's pricing; and the ease with which the clause may be readily understood. Recommendations are made for improvements to each clause.

While contracts are not necessarily instruments designed to flag the legal issues that lie beneath their expressed terms, they may usefully highlight significant legal principles to the 
user. Users of construction contracts are likely to be professionals such as contractors, architects and engineers rather than lawyers. A clause may be perfectly comprehensible to read, but leave the reader unaware of its significance within the law of contract. This paper critiques each contract's time adjustment clause for its readability and the ease with which each clause can be understood. Further conclusions have also been drawn concerning the degree to which each clause reveals the related underlying legal principles.

Terms used in each contract also vary in important ways, which can impede understanding. To clarify: the term client means the same as employer or principle, and the term administrator means the same as engineer or superintendent. Copies of each of the clauses are contained in Appendices 2 - 4.

\section{Risk Allocation for Time Adjustment}

This paper will first determine what the general legal position is, where there are no expressed terms. Each contract is then compared to this base position in order to determine the impact of its clauses.

There are two main expressed contractual conditions which impact on the allocation of risks between parties for EOT claims. These are the listed pre-conditions by which the contractor may claim an EOT, and any time-bar clauses which limit the period in which they may do so. A third associated condition would be the provision of any liquidated damages. These are a genuine pre-estimate of the damages incurred by the client if the project is completed late (Murdoch \& Hughes, 2008). These damages would usually be listed in the specific conditions of contract. In the absence of any specified liquidated damages the client still has the right to claim for general damages. Therefore, the provision of damages has not been critiqued in this paper. In addition to these expressed provisions, there are some other matters relating to general law which also need to be considered. These are the risk of buildability, designer's disclaimer clauses, and the contra-preferentum principle.

\section{The Prevention Principle}

A list of pre-conditions may be included in a contract to allow the contractor a means to claim an EOT for matters which are largely out of their control. If there were no listed preconditions for which the contractor may claim for delays, there remains an implied legal principle. The prevention principle provides that if the employer delays the contractor, the contractor may claim for their contractual completion date to be extended in compensation for the delay. In fact, if there were no legal mechanism to extent time at all, then the due date could not be extended and time would be at large. This would weaken the employer's position because they would no longer have a date from which to enforce liquidated damages, and the contractor would only need to complete the work in reasonable time as deemed by the courts. Reasonable time is likely to be a less demanding requirement to the contractor than the specified completion date (Murdoch \& Hughes, 2008). Therefore, EOT clauses are necessary to provide protection to both the contractor and the employer.

\section{Time-bar Clauses}

A strict time-bar clause may be included in a contract to limit the timeframe by which the contractor can claim for an EOT after a delay has occurred. There has been some debate about whether a time-bar clause should take precedence over the prevention principle. One approach is to conclude that a contractor's failure to comply with a time-bar would constitute a breach of contract. Another is that the prevention principle should only be used to reduce the damages for periods of delay when caused by the principle (Finnie, 2011). However, Lim (2009) has asserted that 'by asking for performance when the promise is guilty of delay is to ask the promisor to do something that he or she never agreed to.' 
Some guidance has been provided from recent New Zealand and Australian case law. Regarding Andrews v Australia and New Zealand Banking Group Ltd [2012] HCA 30, Heintzman (2013) stated:

\begin{abstract}
The central conclusion in Andrews v. ANZ is, of itself, extremely important for the law relating to building contracts. All the clauses in a building contract which provide for monetary payments should be closely examined to see if they impose unlawful penalties. Even those clauses which do not give rise to a breach of contract should be examined. If those payments are out of line with the actual detriment arising from the relevant conduct, potentially they are penalties and unlawful, whether or not they are in relation to a breach of contract.
\end{abstract}

This would indicate that a more liberal approach may be adopted by the courts with regard to the application of time bar clauses.

\title{
Buildability Risk
}

Contractors may be interested to read about the allocation of design risk under traditional building contracts. In a recent paper published by the Society of Construction Law UK 'Design risk allocation under a traditional build contract', (Rosenberg, 2012) highlights that contractors take on the risk of design where it relates to buildability in all but a narrow range of circumstances. Case law examples from within both the New Zealand and the UK legal systems have favoured the employer and engineer over the contractor. For example in the case of Wilkins and Davies Construction Co Ltd v Geraldine Borough [1958], in the Supreme Court, Timaru, New Zealand, the contractor was to sink a sewage tank and pump chamber below ground level, the floor of the tank to be kept dry by pumping from a 44-gallon drum.

However, un-expected ground conditions prevented the sinking of the tank and pump chamber. This resulted in the whole design being abandoned. The contractor claimed for the additional costs associated with the new design. However, the court ruled against the contractor on the grounds that the new work had not been frustrated, nor was it outside the original contract scope (Rosenberg, 2012). Another case in New Zealand involved R M Turton \& Co v Kerslake \& Partners [2000]. In this case the engineer incorrectly specified heat pumps to achieve a certain level of performance. The judge ruled against the contractor's claim for compensation to correct the heat pumps, on the basis that the engineer did not have a duty of care over the contractor, and because the engineer had defined their liability by way of a disclaimer (Rosenberg, 2012). The disclaimer stated: 'By submitting a tender, the tenderer guarantees that the equipment installed will perform as described in the specification/s' (Kennedy-Grant, 2008).

Bailey (2007) also provided that 'Likewise a proprietor who supplies a design to a contractor, which the contractor promises to implement, does not warrant that the design is "buildable".' In fact, where the contract contains no express terms to the contrary, any increased work resulting from unexpectedly difficult ground conditions becomes the contractor's responsibility. This is further reinforced by Hibberd (2006) who, when referring to JCT's Major Project Construction Contract (MP 05) states:

In terms of ground conditions (not expressly covered in DB 05) the default position under MP 05 is that the contractor takes the risk, so any necessary changes do not give rise to a Change formally (i.e. no additional cost recovery or extension of time).

Again, Murdoch \& Hughes (2008, p177) state that 'As a basic principle, it is clear that the risk of adverse site conditions rests with the contractors.'

Bailey (2009) highlighted the disadvantage of this general principle, which is that if a party (e.g. the contractor) encounters severe unexpected difficulties and cannot recoup the 
additional cost involved, they may prefer to default rather than incur the associated additional expense. However he went on to conclude that while a legal doctrine based on good faith has its benefits, in reality it would be difficult to implement in the face of contract law. For example a party claiming a breach of good faith would, in effect, be claiming against a breach of contract.

An exception to the contractor's liability regarding site conditions may be established where documents are provided by the principal at the time of tender, without any disclaimer (Bailey, 2007). An expression of this principle can be found in Standard's Australia's General Conditions of Contract AS4000 - 1997 which provides (Standards Australia):

\title{
25.1 Scope
}

Latent conditions are physical conditions on the site and its near surrounds, including artificial things but excluding weather conditions, which differ materially from the physical conditions which should reasonably have been anticipated by a competent Contractor at the time of the Contractor's tender if the Contractor had inspected:

(a) All written information made available by the Principal to the Contractor for the purpose of tendering;

(b) All information influencing the risk allocation in the Contractor's tender and reasonably obtainable by the making of reasonable enquires; and

(c) The site and its near surrounds.

This principle can also be seen within the JCT editions. When discussing a clause in which the contractor is not responsible for the employer's requirements, or for verifying the adequacy of any design contained within them, Hibberd (2005) states:

\begin{abstract}
The other view of this exclusion is that it only provides the contractor with a limited amount of protection. This is because he has a contractual obligation to give notice if he finds an error, omission or inadequacy in, amongst other things, the Employer's Requirements, which taken together with an implied duty to warn of defects that should be apparent to a competent contractor and an obligation to comply with statutory requirements means a significant level of responsibility is still with the contractor.
\end{abstract}

\section{Disclaimer Clauses}

Importantly, engineers and architects have a duty to take all necessary steps to correct faults in their design which have been brought to their attention. This is dependent however, on their contractual duty, and whether their employment is to produce an initial design only or includes supervision of the works. The engineer/ architect may issue instructions to the contractor via variations, to remedy such design deficiencies (Nissen, 2008), but this obligation nevertheless relies on the contractor to notify them of errors in the first place. As pointed out by Rosenberg (2012), the engineer/ architect may further protect their position by obtaining a proposal from the contractor before issuing a variation, to ensure that the contractor is responsible for any associated costs and/ or time.

\section{The Contra Preferentum Principle}

A further point to consider is the contra preferentum principle, whereby any ambiguities within contract documents err against the party who wrote them. However this principle only applies where the document was drafted by only one party to the contract. Where documents have been written by committee, with parties representative of both contractual sides (such as contractors and engineers) contra preferentum would not apply. Rather, any additional cost and/ or time resulting from the ambiguity could be shared between the parties (Murdoch \& Hughes, 2008). 
Drawings and specifications would not usually be prepared by a committee, but rather by the design team employed by the principal. Therefore the contractor would expect to be reimbursed for any increased cost and/ or time relating to design ambiguities.

An example of expression of this principle can be seen in the following clause from AS4000 - 1997 (Standards Australia) for dealing with document discrepancies:

\subsection{Discrepancies}

Figured shall prevail over scaled dimensions in a discrepancy. Otherwise, if either party discovers any inconsistency, ambiguity or discrepancy in any document prepared for the purpose of carrying out WUC, that party shall give the Superintendent written notice of it. The Superintendent, thereupon, and upon otherwise becoming aware, shall direct the Contractor as to the interpretation and construction to be followed.

If compliance with any such direction under this subclause causes the Contractor to incur more or less cost than otherwise would have been incurred had the direction not been given, the difference shall be assessed by the Superintendent and added to or deducted from the contract sum.

\section{Who Should Bear Design Risk?}

A common principle for allocating contractual risk is to allocate it to the party most capable of managing the risk (Bailey, 2007; Rosenberg, 2012). The client's preference for risk allocation may also be considered.

The client's preference for price surety will influence which type of procurement strategy and form of contract they adopt. Contracts may be categorised as design and build, pure lump sum, lump sum with quantities, re-measurement, and cost reimbursement. A pure lump sum contract is where the contractor is responsible for both the quantum and the rates. In a remeasurement contract the contractor is responsible for the rates, but the client is responsible for the accuracy of the measured quantities. Under a cost reimbursement contract, the contractor is reimbursed for the actual work carried out, so the client adopts the risk of the quantities, the costs and the rates (Kirkham, 2009).

If price surety is a high priority, transferring risk to the contractor will be preferable. However this is likely to increase the contract price, because the contractor may increase their price to account for the risk. For example, if the contractor is to bear the risk of difficult ground conditions, they may base their price for excavation and foundation work on the likelihood of striking poor ground. This will provide the client with price surety, but means that they are likely to pay for the worst case, regardless of whether it eventuates. This could equally apply to the risk of document ambiguities.

Under turnkey contracts (design, build and finance) for public works, the client is more likely to be motivated by price surety over lowest cost (Black, 2005). On the other hand, a private developer with a good understanding of construction may be prepared to accept some of the risk in order to gamble on achieving a lower price. Likewise, a private hospital constructing a series of highly technical extensions may opt for a target cost contract where risks are shared between the parties.

This presents a problem for DZ3910. Unlike the collection of contracts within the FIDIC or JCT series, DZ3910 is a contract which can be either a pure lump sum, re-measure or cost reimbursement contract. 


\section{Risk of Ambiguities within Design Documents}

The professional designer (client's employee), would be the expert most able to manage the risk of design ambiguities. The contractor is expert at pricing and constructing the works, but not design. On this basis, the risk of ambiguities should be allocated to the client by way of their agent (assuming a traditional contract arrangement).

Under a typical design and build contract, the contractor should be responsible for the design (or design elements that the contractor has produced).

\section{Risk of Design Relating to Buildability}

In this case, the contractor should have expert knowledge regarding the buildability of the proposed design. Generally, under any type of contract arrangement (such as lump sum, cost reimbursement or design and build), the contractor would be the most competent to determine whether the design can actually be built.

\section{Comparison of Risk Allocation between Clauses}

In section 2 above we have defined the contractual risks, and where (in theory) the various risks should be allocated. We can now interpret each contract type, to determine how they allocate risks between parties and how this may affect the contractor's pricing.

\section{AS4000}

- Allowable pre-conditions are called qualifying events. These include:

Qualifying cause of delay Means;

(a) Any act, default or omission of the Superintendent, the Principal or its consultant, agents or other contractors (not being employed by the Contractor); or

\section{(b) Other than:}

i) A breach or omission by the Contractor;

ii) Industrial conditions or inclement weather occurring after the date for practical completion; and

iii) Stated in Item 23;

Part (a) and (b) (i) are nothing other than a clarification of the prevention principle. That only leaves an industrial condition or inclement weather as qualifying events. The reader is left to interpret the definition and extent of an industrial condition. I was left wondering whether this means something such as a strike or lock-out as listed in DZ3910, or something more general relating to the construction industry. Importantly, the contractor is left accepting the risk of delay caused by anything else. This would include buildability issues or designer's disclaimers. The contractor needs to be fully aware of their exposure, and either exclude risks in the tender offer or accept it by perhaps increasing their price to allow an amount for acceleration costs that may be required.

- Contains a time-bar clause of 28 days for the contractor to claim for an EOT in Clause 34.3 (b). This is followed by Clause 34.5 which allows the superintendent 28 days to respond. This increases the contractor's risk, in that if they have poor time-management procedures they may lose the opportunity to claim an EOT for an otherwise allowable circumstance (subject to the prevention principle vs. time-bar clause debate mentioned previously). Likewise, if the superintendent fails to respond on time, the contractor's EOT claim will stand, regardless of whether it is valid.

- Clause 34.4 states that when assessing an EOT claim: 
34.4 Assessment when both non-qualifying and qualifying causes of delay overlap, the Superintendent shall apportion the resulting delay to WUC according to the respective causes' contribution.

In assessing each the Superintendent shall disregard the question of whether:

(a) WUC can nevertheless reach practical completion without an EOT; or

(b) The Contractor can accelerate, but shall have regard to what prevention and mitigation of the delay has not been effected by the Contractor.

This clause is perhaps unnecessary, because the evaluation of which delaying events impacted on the programme, and granting an EOT for the qualifying events only, would ineffect be the process in the absence of this expressed clause. Perhaps it provides some useful guidance.

- The risk of ambiguities within design documents remains with the employer under the contra-preferentum principle.

\section{ASTCC}

- Allowable pre-conditions are listed under Clause 2.5.3 as follows:

\subsection{3}

(i) the act or failure to act by the Client, the Contract Administrator, or others engaged by the Client or anyone within any of their control;

(ii) exceptionally bad natural environmental event (including exceptionally bad weather) beyond the parties' control occurring at the project site;

(iii) a government authority action;

(iv) the Contractor suspends the work following an instruction from the Contract Administrator to suspend the work; or

(v) the Contractor suspends the work following non-payment as provided under the termination provision in this contract.

Items (i) and (iv) simply confirm the prevention principle. Item (v) is confirming what is covered by statute under New Zealand's Construction Contracts 2002 regarding consequences for non-payment. This leaves natural disasters and government authority actions. Once again, the contractor accepts the risk for any buildability issues and designer's disclaimers.

- The risk of ambiguities within design documents remains with the employer under the contra-preferentum principle.

\section{DZ3910}

- The acceptable pre-conditions for claiming an EOT are listed under Clause 10.3.1 as follows:

(a) The net effect of any Variation; or

(b) Weather sufficiently inclement to interfere with the progress of the works; or 
(c) Any strike, lockout, or other industrial action; or

(d) Loss or damage to the Contract Works or Materials; or

(e) Flood, volcanic, or seismic events; or

(f) Any circumstances not reasonably foreseeable by an experienced Contractor at the time of tendering and not due to the fault of the Contractor.

These seem to be a reasonable list of pre-conditions. Note that the contract does not state any delay caused by the principle or their engineer. This would still be a claimable delay under the prevention principle. In the absence of any expressed term, the contract relies on users having knowledge of this legal principle. This is an important point, because one of the principles of modern plain English drafting is that the contract wording should be appropriate for the parties using it. Users of a construction contract are likely to be professionals, but without specialist legal knowledge (Ameer Ali, 2008). However in this instance, perhaps it could be deemed as covered under Clause (f).

A further important question here is whether Clause $(f)$ covers matters relating to buildability. A good example of this issue is where the contractor encounters unexpected ground conditions which affect buildability. Guidance is provided by Bailey (2007), who explains what the general legal position is:

If a contractor has promised - in unqualified terms - to construct a building or other structure for a lump sum price, that is what the contractor must do: the agreed price is all that the contractor is entitled to be paid for doing so. It is no excuse for late performance or non-performance that the site conditions which the contractor encountered were worse than it anticipated. In short, the risk of adverse site conditions, whether they be known or latent, is with the contractor. It is therefore only if a contract makes express provision for the payment of additional money in the event of bad ground being encountered that the contractor will be entitled to additional payment (and usually also an extension of time).

The question then is whether Clause 10.3 .1 (f) specifically addresses the issue of buildability. This is further clarified again by Bailey (2007):

\begin{abstract}
The encountering of unforeseen site conditions affords no excuse for not meeting these contractual commitments. It follows that unless a contract makes specific provision for a contractor to be entitled to an extension of time for completion, additional compensation, or both, in the event of adverse site conditions being encountered, the risk of those conditions will remain with the contractor. This is essentially the position adopted by the JCT 05 form, whose clause 2.29 lists exceptionally adverse weather conditions and force majeure as "relevant events", potentially entitling the contractor to an extension of time. But the contract makes no provision for any extension of time or for that matter any increased compensation, in the event of unforeseen bad ground being encountered. Hence the general position applies, i.e. the contractor bears this risk.
\end{abstract}

DZ3910 Clause 10.3.1 (f) also does not specifically state unforeseen ground conditions, or any other matter relating to buildability. Moreover, the general legal position is that a reasonably competent contractor should be able to peruse the documents and investigate the site, and foresee any issues relating to buildability. Consequently, as under JCT 05, the general legal principle applies here too, that the contractor accepts the risk for any buildability issues and designer's disclaimers. 
A further point to consider is that DZ3910 contains a clause 5.19 .3 which states:

If the Contractor does not notify a matter which it reasonably ought to have notified, any Variation arising out of the matter shall be valued by the Engineer as if notice had been given and that notice might reasonably have resulted in the effect of the matter being avoided or minimised.

This Clause expressly shifts the risk to the contractor, unless they notify the engineer of such matters (within a timeframe not yet stipulated).

The risk of ambiguities has been allocated to the contractor for any matters of which they fail to advise the engineer. This increases the contractor's liability from the implied law stance pertaining to the contra preferentum principle. However, this does provide the principal with greater price surety, especially if a time-bar clause requires the contractor to notify any matters within say, 1 month of being awarded the contract. Would this be such a difficult and unusual undertaking for the contractor? In times of a competitive market, contractors may choose to submit bids at or below costs, which they believe to be the likely market price. They then generate claims and variations post-contract in order to recover the shortfall (Heaphy, 2011). This would imply that a contractor's procedure would be to immediately scan the documents for any ambiguities upon being awarded the contract. Furthermore, provided they do carry out this procedure, they are still entitled to any resultant cost and/ or time adjustments, and the principal gains their surety.

An interesting question here is whether the contractor's notification to the principle of any matter 'it ought to' would imply that any associated compensation is then claimable through variations? When it comes to design deficiencies, would this take precedence over the general legal position about buildability? If so, this would certainly benefit the contractor. For example in the case of Wilkins and Davies Construction Co Ltd v Geraldine Borough [1958], relating to the concrete pump dispute discussed earlier, had the contractor notified the engineer that they had a concern about the design, would they have been awarded compensation?

Likewise, in the case of R M Turton \& Co v Kerslake \& Partners [2000] relating to the under specified heat pumps, would Clause 5.19 .3 override the engineer's disclaimer if the contractor raised concerns with the engineer about the capacity of the specified heat pumps?

This does however, have the potential to lead to a ridiculous situation whereby the contractor limits their design risk liability by notifying about all sorts of design matters wherever there could be any possible doubt about its buildability. In order to remove any ambiguity, such clarification should be incorporated into the wording of the clause

- Includes time-bar clauses of 20 Working Days for the contractor to claim an EOT and 20 Working Days for the engineer to respond. However, these are softened with the addition of 'or as soon as practicable thereafter.'

- The risk of ambiguities within design documents remains with the employer under the contra-preferentum principle, subject to clause 5.19.3.

\section{Ease of Understanding}

Before each contract's ease of understanding is evaluated, it is first necessary to understand what it is, in fact, that makes a contract easy to understand. There has been an international movement towards modern plain English drafting. This aims at writing contracts in a manner which expresses rather than impresses. The focus is on removing long-winded complicated legalese and replacing it with clauses which are as simple as possible without losing their legal intent (Ameer Ali, 2008). Some of these principles include: 
1. Having a clear structure which is easy to follow

2. Avoiding the use of words which have multiple meanings such as shall or and/or

3. Words being used in their ordinary sense

4. Using short simple sentences (average of 20 words per sentence is appropriate).

Each clause should be as simple as possible without losing its legal intent.

With this in mind, we can investigate the clauses in each contract:

\section{AS4000}

- The contents page is not set out in a project management-type structure, nor does it follow a chronological order. For example, out of 43 items, item 26 is 'Setting out the works'. This is followed by item 27 'Cleaning up'.

- Uses the word shall which has multiple meanings. This is interesting because the Australian and New Zealand governments seem to have moved away from using such words. For example, Ameer Ali (2008) noted:

there are no "shall" or "and/or" in the New South Wales, Queensland and Victorian Acts. Nor is there any in the New Zealand Construction Contracts Act 2002. And instead of "null and void" the Queensland Act, for example, uses just "void".

Interestingly, AS4000 Clause 34 contains shall ten times!

- Clauses 34.1 - 34.5 contain twelve sentences with an average word count of 25 words per sentence and a maximum of 42 words. This seems reasonable.

- Abbreviations are used, which forces the reader to look up meanings in the glossary. For example WUC means 'work under the contract'. This does not seem excessive. But to find the acceptable pre-conditions for claiming an EOT, I had to look up qualifying event in the glossary. There it lists all the acceptable events, including 'Stated in Item 23;' So next I had to look up Item in the glossary, which for some reason is not listed in alphabetical order like the other terms, which provided 'Means an Item in Annexure Park A;'. Besides the fact that there is a spelling mistake (park should be part), I found it a long and cumbersome process to find something as vitally important as the preconditions for claiming EOT.

\section{ASTCC}

- ASTCC adopts a project management structure for its contents. Its author, Ameer Ali (2008) promotes this by stating that it 'will lead to greater efficiency during contract administration.' This very quickly becomes evident as I turn to the contents page, see a sub-heading for time and am immediately directed to page 9 . Easy!

- There is no internal cross-referencing.

- Words have been used in their ordinary sense without legal jargon. An example is the heading of Clause 2.5 'Adjusting the date for completing the work'. Not only is this title clear to any reader, but it also infers that time may be adjusted both positively and negatively, rather than just being 'extended'.

- There are no words with multiple meanings. 
- Clause 2.5.2 states that the 'Contract Administrator must then assess and decide if the date for completing the work is affected.' This means the same as AS4000's clause 34.4. However it uses sixteen words instead of seventy.

- Clauses 2.6, contains ten sentences with an average word count of 18 words per sentence, and a maximum of 25 words. This is less than the recommended average word length of 20 discussed earlier, and provides for easy reading.

\section{DZ3910}

- The contents page is not set out in a project management-type structure, although it does follow a roughly chronological order. It has the longest contents page, at three pages. This perhaps reflects the size of the contract, which is 148 pages long. (AS4000 is 39 pages and STCCC is 19 pages).

- Uses the word shall which has multiple meanings. Clause 10.3.contains shall nine times. Clause 10.3.4 alone contains three:

10.3.4

Upon receipt of notice of a claim for extension of time the Engineer shall investigate the claim. The Engineer shall within 20 Working Days or as soon as practicable thereafter determine whether or not the Contractor is fairly entitled to an extension and shall notify the Contractor of his or her decision.

- Clauses 10.3 contains 20 sentences with an average word count of 24 words per sentence, and a maximum of 58 words. While the average word count seems reasonable, there are two sentences with over 50 words, which perhaps could be better structured.

- There are internal references for Clauses 10.3.1 and 10.3.2 to the Guidelines section. Here there is another whole page of writing in relation to Clause 10.3 for Extension of Time. The introduction to the Guidelines state that they 'do not have contractual status' so they have not been evaluated in this paper. However, it is worth noting that this is the only contract which includes a guidelines section. Surely any contract should be drafted in a manner which is clear from the onset, and does not require a further document to explain how to read it.

- Clause 10.3.6 (below) is an example of a clause with excessively long sentences. It describes information about compensation for the contractor's acceleration costs, which is not expressed in either of the other contracts.

10.3.6

In any circumstances in which the Engineer determines that the Contractor, is entitled to an extension of time the Engineer may, subject to the agreement of the Principal and the Contractor, approve the taking by the Contractor of steps to accelerate the work. In such case the Engineer shall grant either no extension of time or such lesser extension as may be agreed. The Contractor shall be entitled to be paid such sum as may be agreed or failing agreement such sum as is reasonable to compensate the Contractor for the additional Cost of the agreed steps taken to accelerate the work and of the effect of those steps on other aspects of the work together with an allowance for profit. The sum payable shall be calculated in accordance with 9.3.6, 9.3.8, 9.3.9, and 9.3.14.

Perhaps the other contracts do not need to address this, because parties to a contract are free to agree to anything lawful. It seems fairly obvious that any agreed costs for valuing a variation resulting from acceleration costs would be calculated in accordance with the 
clauses for dealing with valuing variations. An alternative wording to this clause is provided below:

10.3.6

Where all parties mutually agree, the Engineer may instruct the Contractor to accelerate their work. Where any change in cost cannot be agreed they will be calculated in accordance with 9.3.6, 9.3.8, 9.3.9, and 9.3.14. Any associated extension time may be adjusted or deleted by the Engineer in reflection of the acceleration.

\section{Recommendations}

\section{AS4000}

- Adopt a project management-type structure for the contents.

- Replace any words which have multiple meanings. For example replace shall with must, may, or will on every occasion.

- List the qualifying events for claiming an EOT under clause 34 (which deals with time), with reference to any additional events directly to the Annexure Part $A$.

- Include a clarification explaining how the risks of buildability issues are to be allocated. Also provide clarification that any clauses are subject to designer's disclaimers.

- Clarify what is meant by 'industrial condition' as a qualifying event.

\section{ASTCC}

- Include a clarification explaining how the risks of buildability issues are to be allocated. Also provide clarification to explain that all clauses are subject to designer's disclaimers.

\section{DZ3910}

- Adopt a project management-type structure for the contents. An example of an alternative structure is provided in Appendix 1.

- Replace any words which have multiple meanings. For example replace shall with must, may, or will on every occasion.

- Include a clarification explaining how the risks of buildability issues are to be allocated. Also provide clarification that any clauses are subject to designer's disclaimers.

- Re-structure some of the longer sentences (e.g. over 40 words long) to make them more readable.

- Where possible, remove the Guidelines by re-writing contract clauses in such a way that no further guidance is required.

\section{Opportunity for Further Research}

There seems to be a general misunderstanding in industry about the risk allocation of buildability under a construction contract. When writing this paper, I was surprised to learn about this matter. I asked some of my peers, who included architects, contractors, engineers and quantity surveyors the following question 'If a contractor submits a lump sum price to construct a building, based on drawings and specifications, and then encounters unexpected ground conditions which increase the cost of the work, who pays?' They all answered that the client would pay, because the unexpected ground would be treated as an unforeseen circumstance. I was not surprised by the responses, because that is how I would have answered the same question a few weeks earlier. In fact, a professional quantity surveyor said he had just authorised a sizable sum of money to a contractor for that exact reason.

It would be interesting to carry out a survey amongst industry practitioners to gauge their interpretation of this issue. The amount of money paid out to contractors for unexpected ground conditions could also be researched. Importantly, the issue is not that the client is being 'ripped off' by paying more than they should, because if none of the parties have an understanding of the legal position, the contractors have not priced for the risk in the first 
place. Instead it seems to be a matter of awareness. Once contractors become aware of the risk, they are likely to exclude it from their price anyway. It is still an important point however, because if the status quo is to remain, contractors will continue to expose themselves to the risk of paying additional costs for which they have not allowed, such as in the case of $R M$ Turton \& Co v Kerslake \& Partners [2000].

\section{Conclusions}

ASTCC is the easiest contract to interpret, followed by AS4000 and then NZS3910. This assessment was made by comparing the numbers of words with double meanings in each contract; the number of words used per sentence; the amount of internal cross-referencing; and the clarity of the contract structure.

There are similarities between all three contracts in the allowable pre-conditions for a contractor to claim a time adjustment, and none of the contracts expressly state which party is to bare the risk of buildability, or address the risk of a designer's disclaimer clause. All three contracts adopt the principle of contra preferentum, which means that the employer carries the risk of variance due to ambiguities in design documentation. Due to their similarities of risk allocation, all of the contracts provide the employer with a similar amount of price surety.

AS4000 is the only contract to contain a stringent time-bar clause for the contractor to claim a time adjustment. ASTCC requires the contractor to apply 'immediately' and DZ3910 provides a time-bar of 20 working days or as soon as practicable. None of the contracts provide whether their timing requirements take precedence of the prevention principle or any other ground for claiming a time adjustment.

An alternative contents structure for DZ3910, using a project management method, is recommended.

\section{References}

Ameer Ali, N. (2008) 'Modern plain English drafting and construction: the Malaysian subcontract model terms'. Society of Construction Law UK. D90. http://www.scl.org.uk/node/828 October 2012

Bailey, E. (2009) A doctrine of good faith in New Zealand contractual relationships. Master's thesis, University of Canterbury, Canterbury, New Zealand. http://ir.canterbury.ac.nz/bitstream/10092/2862/1/Thesis fulltext.pdf October 2012.

Bailey, J. (2007) 'What lies beneath: site conditions and contract risk', Society of Construction Law UK. 137. http://www.scl.org.uk/node/608 October 2012

Black, M. (2005) 'Design risk in FIDIC contracts', Society of Construction Law UK. http://www.scl.org.uk/node/579 October 2012

Finnie, D. (2012) 'Contract Delay what is it and how are we Performing?', Australasian Journal of Construction Economics and Building, 12 (1)

Heaphy, I. (2011) 'Do target cost contracts deliver value for money?' Society of Construction Law UK. D126. http://www.scl.org.uk/do-target-cost-contracts-deliver-value-money-1 October 2012

Heintzman, Thomas G. (2013) 'Andrews v ANZ: what are the consequences for building contracts?' Association of Corporate http://www.lexology.com/library/detail.aspx?g=5c212e12-b283-49d2-a872-1e2544854850

October 2012

Hibberd, P. (2005) 'Is single-point design responsibility under JCT 05 illusory?' Society of Construction Law UK. D73. http://www.scl.org.uk/node/806 October 2012

Finnie, D (2013) 'Comparison of time adjustment clauses between DZ3910, AS4000 and STCC', Australasian Journal of Construction Economics and Building, 13 (1) 66-84 
Kennedy-Grant, T. (2008) 'Cross fertilisation - New Zealand developments in construction law and adjudication'. Society of Construction Law Singapore. http://www.kennedygrant.com/docs/sing oct 08.pdf October 2012

Kirkham, R. (2009) Ferry and brandon's cost planning of buildings, $8^{\text {th }}$ ed, Blackwell

Lim, T. (2009) 'Essence of Time in Construction Contracts', The Australasian Journal of Construction Economics and Building, 9 (2)

Murdoch, J. and Hughes, W. (2008) Construction contracts law and management, $4^{\text {th }}$ ed, Taylor \& Francis

Nissen, A. (2008) 'The designer's duty - time for review'. Society of Construction Law UK. 151. http://www.scl.org.uk/designers-duty-time-review-0 October 2012

Rosenberg, K. (2012) 'Design risk allocation under a traditional build contract'. Society of Construction Law UK. D140. http://www.scl.org.uk/design-risk-allocation-under-traditionalbuild-contract October 2012

Standards Australia (1997) AS4000 - 1997 General conditions of contract. Standards Australia

Standards New Zealand (2012) Release of draft standard for public comment - DZ3910 conditions of contract for building and civil engineering construction. http://www.shop.standards.co.nz/docserv/drafts/3910 pc final draft V2.pdf October 2012

\section{Appendix 1: Alternative contents structure for DZ3910 using a project management method}

\section{Part A: Agreement, Definitions, and Provisions}

1. Contract Agreement (Second Schedule)

2. Specific conditions of contract (First Schedule)

3. Special conditions of contract and other conditions of contract (First Schedule)

4. Conditions of Tendering

5. Other Schedules:

5.1.1. Form of Contractor's performance bond (Third Schedule)

5.1.2. Form of Principal's bond (Fourth Schedule)

5.1.3. Form of Contractor's bond in lieu of retentions (Fifth schedule)

5.1.4. Form of producer statement - construction (Sixth schedule)

5.1.5. Information as to contract works insurance (Seventh schedule)

5.1.6. Information as to public liability insurance (Eighth schedule)

5.1.7. Information as to the Contractor's construction machinery insurance (Ninth schedule)

5.1.8. Information as to the Contractor's motor vehicle insurance (Tenth schedule)

5.1.9. Information as to Contractor's professional indemnity insurance (Eleventh schedule)

6. Law, currency and language

7. Application

8. Definitions

9. General

\section{Part B Standard Terms of Contract}

1. General obligations, contract administration, and variations

1.1. The Contract

1.1.1. Type of contract

1.1.2. Lump sum contract

1.1.3. Measure and value contract

1.1.4. Cost reimbursement contract

Finnie, D (2013) 'Comparison of time adjustment clauses between DZ3910, AS4000 and STCC', Australasian Journal of Construction Economics and Building, 13 (1) 66-84 
1.1.5. Road or term maintenance contracts

1.1.6. Local authority contracts

1.1.7. Evidence of contract

1.1.8. Documents prepared by the Engineer of Principal

1.1.9. Documents prepared by the Contractor

\subsection{Contractor's duties}

1.2.1.1. General responsibilities

1.2.1.2. Compliance with laws

1.3. Engineer's powers and responsibilities

1.3.1.1. Duties of the Engineer

1.3.1.2. Appointment of the engineer

1.3.1.3. Role of the engineer

1.3.1.4. Engineer's representative

1.3.1.5. Inspection, recording, measuring and testing

1.3.1.6. Removal and making good

1.3.1.7. Certification

1.3.1.8. Suspension of the work

1.3.1.9. Emergency work

1.3.2. Service of notices

\section{Time}

2.1. Commencement

2.2. Late supply by the Principal

2.3. Due date for completion

2.4. Contractor's obligations for the programme

2.5. Extension of time (change to adjustment of time)

2.6. Certification of Practical Completion

2.7. Damages for late completion

2.8. Bonus for early completion

2.9. Occupancy by the Principal

\section{Financial}

3.1. Indemnity and insurance

3.1.1. Indemnity

3.1.2. Contractor to insure Contract Works and Materials

3.1.3. Contractor to insure Contractor's construction machinery

3.1.4. Contractor to insure against public liability risks

3.1.5. Professional indemnity insurance for Contractor's design

3.1.6. Contractor's insurance general

3.1.7. Principal's option to insure Contract Works and Materials

3.1.8. Principal's option to insure public liability

3.1.9. Principal's insurances - General

3.2. Payments

3.2.1. Contractor's payment claims

3.2.2. Progress Payment Schedules

3.2.3. Retention monies

3.2.4. Final payment claim

3.2.5. Final Payment Schedule

3.2.6. Effect of Final Payment Schedule

3.2.7. Interest

3.2.8. Cost Fluctuations

3.2.9. Provisional Sums

3.2.10. Prime Cost Sums

3.2.11. Contingency sums

Finnie, D (2013) 'Comparison of time adjustment clauses between DZ3910, AS4000 and STCC', Australasian Journal of Construction Economics and Building, 13 (1) 66-84 
3.2.12. Goods and services tax

3.3. Variations

3.3.1. Variations permitted

3.3.2. Variation orders

3.3.3. Valuation of Variations

3.3.4. Daywork

3.3.5. Unforeseen physical conditions

\section{Quality and other Obligations}

4.1. Contractor's obligations for quality management

4.2. Period of defects liability

4.3. Defects liability

4.4. Defects Liability Certificate

4.5. Effect of Defects Liability Certificate

4.6. Guarantees

4.7. Contractor's representative

4.8. Control of employees

4.9. Care of the site and works

4.10. Possession of the site

4.11. Protection of persons and property

4.12. Setting out

4.13. Materials, labour and plant

4.14. Patents and royalties

4.15. Underground and above ground utilities

4.16. Treasure

4.17. Clearance of site

4.18. As-built drawings, operation and maintenance manuals

\section{Subcontracting and other Contractors}

5.1. General

5.2. Nominated subcontractors (change to Other contractors)

5.3. Contractors obligations for separate contractors

\section{Termination}

6.1. Default by the Contractor

6.2. Default by the Principal

6.3. Frustration

\section{Resolution of Disagreement}

7.1. General

7.2. Engineer's review

7.3. Mediation

7.4. Arbitration

7.5. Suspension during dispute

7.6. Award of interest

\section{Appendix}

A. Cost fluctuation by indexation

B. Construction contracts in public roads

1.B.1. Interpretation

1.B.2. Engineer's powers and responsibilities

1.B.3. Time for completion

C. Term maintenance contracts (including road maintenance contracts)

1.C.1. Interpretation

1.C.2. General obligations

Finnie, D (2013) 'Comparison of time adjustment clauses between DZ3910, AS4000 and STCC', Australasian Journal of Construction Economics and Building, 13 (1) 66-84 
1.C.3. Underground and above ground utilities

1.C.4. Engineer's powers and responsibilities

1.C.5. Time for completion

1.C.6. Defects liability

1.C.7. Payment

D. Obtaining of license by the Contractor

9. Guidelines (remove in preference of clarifying terms within body of contract)

10. Index

\section{Appendix 2: AS4000-1997 Clause 34.1-34.5}

34 Time and progress

\subsection{Progress}

The Contractor shall ensure that WUC reaches practical completion by the date for practical completion.

34.2 Notice of delay

A party becoming aware of anything which will probably cause delay to WUC shall promptly give the Superintendent and the other party written notice of that cause and the estimated delay.

34.3 Claim

The Contractor shall be entitled to such extension of time for carrying out WUC (including reaching practical completion) as the Superintendent assesses ('EOT'), if:

(a) The Contractor is or will be delayed in reaching practical completion by a qualifying cause of delay; and

(b) The Contractor gives the Superintendent, within 28 days of when the Contractor should reasonably have become aware of that causation occurring, a written claim for an EOT evidencing the facts of causation and of the delay to WUC (including extent).

If further delay results from a qualifying cause of delay evidenced in a claim under paragraph (b) of this subclause, the Contractor shall claim an EOT for such delay by promptly giving the Superintendent a written claim evidencing the facts of that delay.

34.4 Assessment

when both non-qualifying and qualifying causes of delay overlap, the Superintendent shall apportion the resulting delay to WUC according to the respective causes' contribution. In assessing each the Superintendent shall disregard question of whether:

(a) WUC can nevertheless reach practical completion without an EOT;

or

(b) The Contractor can accelerate, but shall have regard to what prevention and mitigation of the delay has not been effected by the Contractor.

34.5 Extension of time

Within 28 days after receiving the Contractor's claim for an EOT, the Superintendent shall give to the Contractor and the Principal a written direction evidencing the EOT so assessed. If the Superintendent does not do so, there shall be a deemed assessment and direction for an EOT as claimed. Notwithstanding that the Contractor is not entitled to or has not claimed an EOT, the Superintendent may at any time and from time to time before issuing the final certificate direct and EOT.

\section{Appendix 3: ASTCC Clause 2.5}

2.5 Adjusting the date for completing the work

Finnie, D (2013) 'Comparison of time adjustment clauses between DZ3910, AS4000 and STCC', Australasian Journal of Construction Economics and Building, 13 (1) 66-84 
2.5.1 The Contractor must notify the Contract Administrator in writing immediately and show the impact on the programme and date for completing the work:

(i) if the Contractor cannot start the work on the date for starting the work; or

(ii) whenever there is any disruption to the Contractor's progress of the work.

2.5.2 The Contract Administrator must then assess and decide if the date for completing the work is affected.

2.5.3 Provided the delay is not due to any breach by the Contractor, the Contract Administrator may adjust the date for completing the work in an adjustment of time certificate due to the following reasons:

(i) the act or failure to act by the Client, the Contract Administrator, or others engaged by the Client or anyone within any of their control;

(ii) exceptionally bad natural environmental event (including exceptionally bad weather) beyond the parties' control occurring at the project site;

(iii) a government authority action;

(iv) the Contractor suspends the work following an instruction from the Contract Administrator to suspend the work; or

(v) the Contractor suspends the work following non-payment as provided under the termination provision in this contract.

\section{Appendix 4: DZ3910 Clause 10.3}

\subsection{Extension of time}

10.3.1 ' $G$ '

The Engineer shall grant an extension of the time for completion of the Contract Works or for any Separable Portion if the Contractor is fairly entitled to an extension by reason of:

(a) The net effect of any Variation; or

(b) Weather sufficiently inclement to interfere with the progress of the works; or

(c) Any strike, lockout, or other industrial action; or

(d) Loss or damage to the Contract Works or Materials; or

(e) Flood, volcanic, or seismic events; or

(f) Any circumstances not reasonably foreseeable by an experienced contractor at the time of tendering and not due to the fault of the Contractor.

\subsection{2 'G'}

The Engineer shall not be bound to grant an extension unless:

(a) The Contractor notifies the Engineer that it claims an extension and states the grounds for the extension; 
(b) The notice is given within 20 Working Days after the circumstances arise which are relied on as the grounds for extension, or as soon as practicable thereafter;

(c) The notice either gives details of the period of extension sought or is followed within a reasonable time by a further notice giving such details.

10.3.3

Where the effect of any ground for an extension is of a continuing nature, the Contractor may give more than one notice, each claiming a specific period of extension on that ground.

10.3.4

Upon receipt of notice of a claim for extension of time the Engineer shall investigate the claim. The Engineer shall within 20 Working Days or as soon as practicable thereafter determine whether or not the Contractor is fairly entitled to an extension and shall notify the Contractor of his or her decision.

\subsection{5}

Upon receipt of details of the period of extension sought by the Contractor the Engineer shall, if he or she has determined that the Contractor is fairly entitled to an extension, then determine the period of the extension and notify the Contractor of his or her decision as soon as practicable.

\subsection{6}

In any circumstances in which the Engineer determines that the Contractor, is entitled to an extension of time the Engineer may, subject to the agreement of the Principal and the Contractor, approve the taking by the Contractor of steps to accelerate the work. In such case the Engineer shall grant either no extension of time or such lesser extension as may be agreed. The Contractor shall be entitled to be paid such sum as may be agreed or failing agreement such sum as is reasonable to compensate the Contractor for the additional Cost of the agreed steps taken to accelerate the work and of the effect of those steps on other aspects of the work together with an allowance for profit. The sum payable shall be calculated in accordance with 9.3.6, 9.3.8, 9.3.9, and 9.3.14.

10.3.7

The Contractor shall not be entitled to compensation for time-related Costs where an extension of time is granted on grounds other than the net effect of a Variation. 